\title{
Theodore Harold Maiman and the invention of laser
}

\section{Andrew Rawicz}

Andrew H. Rawicz, "Theodore Harold Maiman and the invention of laser," Proc. SPIE 7138, Photonics, Devices, and Systems IV, 713802 (18 November 2008); doi: 10.1117/12.817966

SPIE. Event: Photonics, Devices, and Systems IV, 2008, Prague, Czech Republic 


\title{
Theodore Harold Maiman and the invention of Laser
}

\author{
Andrew H. Rawicz \\ Simon Fraser University, Burnaby, BC V5A 1S6, Canada
}

\begin{abstract}
In his 1917 "On Quantum Theory of Radiation" paper Albert Einstein introduced the concept of amplification of radiation through stimulated emission with coherence. This concept had not been applied in practice until 1952 when Joseph Weber, followed by Townes, Basov and Prokhorov, developed the theory and started working on the construction of masers. The first maser was demonstrated by Townes' team in 1953. Many researchers began thinking about making an "optical maser", but the transition from centimeter to nanometer waves posed a problem. Well funded researchers in the USA and Soviet Union put their efforts into making an "optical maser". In May 16, 1960 an unknown and underfunded researcher, Theodore Harold Maiman, won the race and demonstrated a fully functional ruby laser. The scientific world was astonished by its simplicity and elegance. Maiman's short paper describing the invention appeared immediately in Nature magazine. This invention caused an avalanche of new laser developments followed by the growing number of applications in almost all fields of our lives. Ted Maiman died in 2007 in Vancouver, just 13 days before the $47^{\text {th }}$ anniversary of the invention of the laser. The intention of this paper is to focus on the life of the scientific maverick and great man.
\end{abstract}

Keywords: Theodore Maiman short biography, invention of laser,

\section{INTRODUCTION}

Childhood - Theodore Harold Maiman was born on the $11^{\text {th }}$ of July 1927 in California. Soon after, his father Abe, an electronics engineer, got a job offer in Colorado and the family moved to Denver. Here Ted with his sister Estelle and parents lived surrounded by his extended family in a triplex owned by his maternal grandparents. As a child he was not much different from his contemporaries and it would be then very difficult to predict that Ted would become one of the greatest inventors of the twentieth century. As a young boy he was curious, adventuresome and sometime creative, and most of all he was hyperactive. The excess of energy transformed sometimes into restlessness, mischief, or - had it been available then, made Ted a top candidate for Ritalin treatment.

Early in his youth, Maiman developed a very skeptical personality. Critical about other people's statements, he always demanded confirmation, usually through experiments. From his childhood memories, his first experiment was with light, albeit incoherent. He did not believe his mother when she told him that the refrigerator light was turning off when the door was closed. In order to settle the matter he crawled inside of refrigerator and the door was shut behind him. He was right - the switch was defective. This experiment did not start his scientific career, but it nevertheless enforced his critical approach to everything.

In school he was known as a trouble maker. One teacher generously said: "Well, there is one thing about Theodore, it does not matter whether he is working on a math problem or raising the roof - he puts his whole heart and soul into it" (source?). Another teacher who recognized that Maiman's restless misbehaviour was caused by the fact that he found lessons too easy and thus boring, channeled his precociousness by giving him special assignments. It worked; he never got into trouble in her class.

When talking about the elements of his past which informed his becoming a scientist and inventor, Maiman often mentioned the influence of his father Abraham. Abe, as he preferred to be called, was a very inventive electrical engineer. Most of his professional carrier he worked in major telecommunication companies, such as AT\&T and Bell Telephone Laboratories. Maiman said: "It was my father who introduced me to the world of technology and had a very profound and positive influence on my professional interests".

Abe always kept a small electronics laboratory, either in the basement or in the attic of their home, wherever they lived. It was there that Maiman got his lifelong inspiration.

Abe invented a number of electrical devices that are still used today. Among them are: a DC-to-DC converter, an electronic stethoscope, and advances in the sound system design for Hi-Fi radio system. When Abe was designing the

Photonics, Devices, and Systems IV, edited by Pavel Tománek, Dagmar Senderáková, Miroslav Hrabovský, Proc. of SPIE Vol. 7138, 713802 - @ 2008 SPIE · CCC code: 0277-786X/08/\$18 · doi: 10.1117/12.817966 
first dial-by-radio system, a technological breakthrough, his boss stubbornly said : "It will not work". Of course it worked.

Observing his father's creative endeavours and the skepticism with which they were viewed, Ted learned that the public, even an authoritative scientific one, is not necessarily correct in its assessment of fresh new ideas.

In his autobiography The Laser Odyssey, Maiman says: "Abe and I were very close. We would oft-times play chess together and we had special bonds between us because we could spend hours discussing his inventive projects in some details, as well as electronics in general. In that sense, he was probably closer to me than my sister, Estelle, who in turn was much closer and communicative with my mother". (p.\#?)

Maiman got his first job when he was 12, in an electrical appliance repair shop in Denver. Initially the owner of this shop did not believe that Maiman could manage repair work - he asked him to sweep floors. It took only a few days to prove that Maiman's knowledge of electronics and electricity, which he acquired in his father's laboratory, was more than sufficient to repair everything brought in by clients. From then on, during his schooling years, Maiman was always kept busy with his after school employment. In high school he added clarinet lessons and joined the school band. To ensure that he was left with no spare time at all, he also enrolled in night courses in radio theory from the University of Colorado's Extension Program.

In the latter part of his $17^{\text {th }}$ year Maiman enlisted in the US Navy. He was accepted into the radar and communications training program, which furthered and strengthened his electronics knowledge.

University time - While working at National Union Radio, Maiman observed in the darkness an eerie glow emanating from vacuum tubes. The tube designers disagreed about the reason for the glow, and this frustrated Maiman as he found himself unable to properly argue for his own explanation. Stronger grounding in physics appeared to be necessary. Maiman thus did undergraduate course work in both engineering and physics at the University of Colorado, graduating with a Bachelor of Science Degree in Engineering Physics. Besides receiving this desired education, Maiman valued particularly the mentorship of the dean of the UC engineering school, Dean Lester.

One of the most memorable pieces of advice the dean gave him was:

"When you try to solve a problem and run into a brick wall - do not just quit". "Go around the obstacles - if going to the right does not work, try to the left and if still thwarted go over the top or try tunneling underneath. Maybe, you have to go head-on and drill through". (The Laser Odyssey)

Stanford University was Maiman's first choice for graduate studies, but after being rejected to their physic's program, he enrolled at Columbia University in New York, his second choice. He did not particularly like the "concrete jungle" environment there and after one year of Columbia he tried Stanford Physics again, but was again rejected. Following the advice to "go around obstacles" he applied to Electrical Engineering and got accepted. The idea was to get to Physics through the "back door". The strategy worked. Maiman got his Masters of Science in Electrical Engineering and applied for the third time to the Stanford Physics Department. This time he was accepted and entered their PhD program.

After finishing course work Maiman met Willis Lamb, a brilliant theoretical physicist, and Lamb agreed to be his thesis supervisor. Lamb hired Maiman to build an experiment that would verify a small atomic level displacement, Lamb-Shift, in an elevated level of the helium atom. The first experimental set-up gave inconclusive results; the signal-to-noise figure was too low. The system relying on the vacuum suffered continuously from contamination, vacuum leaks, and light leakage. The challenge was enormous, but Maiman was scientifically and psychologically equipped for tackling such difficulties. After simplifying the apparatus, so much that it made Lamb nervous, Ted triumphed and was able to get beautiful, clear resonance signals, with high signal-to-noise ratio. This experiment resulted in a $\mathrm{PhD}$ degree for Maiman and a joint paper with Willis Lamb in the Physical Review (Physical Review, Vol 105. No. 3, January 15, 1957)

Real World- A decision now was to be made: "What next?" Maiman was not particularly interested in pure academic work and thought about finding a research position in the industry; since he did not like formal teaching. After an around-the-world voyage in August 1955, Maiman went to work at Lockheed Aerospace. It was a mistake and a disappointment. Lockheed was collecting new, promising scientists to bid on a substantial, $\$ 250 \mathrm{M}$ government contract; however, Martin Marietta, the least probable winner, won this contract. The new laboratory started to crumble and people began to leave. Irwin Hahn, a physics professor at Berkeley, who was also a consultant to the industry and 
Maiman's friend, arranged a contact with Hughes Research Laboratory in Culvert City, California. Maiman secured his job in the Hughes Atomic Physics department in Quantum Physics section.

Very soon he was selected to head the maser project and deliver the special state-of-the-art ruby maser, a microwave amplifier. The project was contracted by the United States Army Signal Corps.

The standard solid state masers at that time were large, heavy and totally impractical. The main component was a large electromagnet, weighing almost 2.5 tons, and associated with this "elephant" was a cryogenic-cooling system significantly lowering the temperature of the ruby crystal. This cryogenic system used liquid helium which is costly and difficult to store. Maiman's ingenuity intervened again and the maser had entirely been redesigned.

Maiman "fabricated a ruby crystal into a rectangular block approximately $3 \mathrm{~mm}$ thick by about $7 \mathrm{~mm}$ square. Highly conductive silver paint was painted and baked on the ruby. The pumping power needed to activate the ruby into maseraction was provided by a small klystron. The magnetic field was easily furnished by a 340 gram AlNiCo permanent magnet. The whole assembly, including the double Dewar, wave-guide coupling, maser cavity and associated microwave accessories weighted $12.5 \mathrm{~kg}$; 200 times lighter than its predecessor" source?

The performance and practicality of the new design exceeded the expectations of the contractor, the United States Army Signal Corps. The product was delivered on time. Ted's final adaptation was to redesign the maser in such a way that cryo-cooling was not needed.

\section{INVENTION OF LASER}

As mentioned earlier, the theoretical possibility of creating coherent light was proposed by Albert Einstein in his 1917 paper. In his 1940 doctoral dissertation, V.A. Fabrikant specified and calculated the conditions necessary for light amplification by stimulated emission. He evaluated the necessary population inversion and proposed using resonant cavity to organize the photons. He also proposed the use of a helium discharge lamp to optically pump gaseous cesium. He did not succeed in making the laser, but set the foundation for later researchers. People were not ready for the laser yet. In December 1958 Schawlov and Townes published a technical paper which proposed a potassium vapour-based infrared laser. The paper was incorrect and the idea unworkable, but it started the race.

Many well funded US research groups entered the race quite early, such as TRG (Gould), Columbia Radiation Laboratory (Townes), Bell Labs (Schawlov and Sanders), MIT, IBM, GE, RCA and Westinghouse. They were all well ahead of Hughes, where in 1959 Maiman was just finishing the ruby maser. Despite the lateness and lack of moral and financial support in Hughes, Maiman decided to switch to laser work. In his personal communications he always emphasized that he did not join the race. He simply thought that he could make the laser using the material which he knew well from his earlier research on the ruby maser. He studied microwave and optical properties of synthetic rubies and found this material simple and understandable enough to try it for laser work. In his article to the Physical Review Letters (April 22, 1960), it was visible that he already had the "critical mass" of knowledge to build a ruby laser.

Maiman built the laser in an astonishingly short time of 9 months with the help of Irnee D'Haenens, a Masters' student at the University of Southern California. Maiman insisted that the laser must be made of commercially available components. It took him a few months to identify the most powerful helical flash lamps used in the industry. He had the "pink" ruby rod from his earlier maser research. He deposited silver at one end of the rod. Because they could not make a partially transmissive dielectric mirror at the other end of the ruby rod in order to create a resonant cavity, Maiman deposited the silver mirror again and drilled a little hole in the centre of it to let the resulting coherent light out. On May $16^{\text {th }} 1960$ after checking and re-checking if everything was alright, Maiman charged the high voltage capacitor in the flash lamp power supply to about 500 volts and pressed the "on" switch. A trace of red light pulse was registered on a Hughes Memoscope.

$$
\begin{aligned}
& \text { "But, when we past } 950 \text { volts on the power supply, everything changed! The output trace } \\
& \text { started to shoot up in peak intensity and the initial decay time rapidly decreased. Voila. That } \\
& \text { was it! The laser was born". (The Laser Odyssey) }
\end{aligned}
$$

At this time it may be useful to explain the difference between natural ruby gemstones and synthesized crystals used in masers and later in the laser work. Natural rubies have a high concentration $(0.5 \%)$ of chromium in corundum matrix, which causes their deep, dark red "ruby" colour. The re-absorption of fluorescent photons is thus quite high. 
Synthesized ruby crystals used for masers and later for lasers are "pink" and have about ten times lower doping with chromium (about 1 part in 2000). When a green photon $(550 \mathrm{~nm}$ ) impinges on and is absorbed by the ruby, a chromium ion is raised from its ground state $\left({ }^{4} \mathrm{~A}_{2}\right)$ into a broad, excited band $\left({ }^{4} \mathrm{~F}_{2}\right.$ in figure below). The return from the excited level can occur in two ways: spontaneous emission and another process. This competing process utilizes thermal vibrations of the lattice to interact with the excited ion and transfer most of its energy to another slightly less excited level called "metastable". The chromium ions enjoy spending relatively long time on this fluorescent level $\left({ }^{2} \mathrm{E}\right)$ before they fall and radiate two groups of red photons $(694.3$ and $692.9 \mathrm{~nm})$ due to the fluorescent level split. When the excitation becomes very intense the population of this metastable state may exceed the ground state: the condition of inverse population and consequently amplification by stimulated emission. (T.H. Maiman Stimulated Optical Radiation in Ruby. Nature, no. 4736, August 6, 1960).
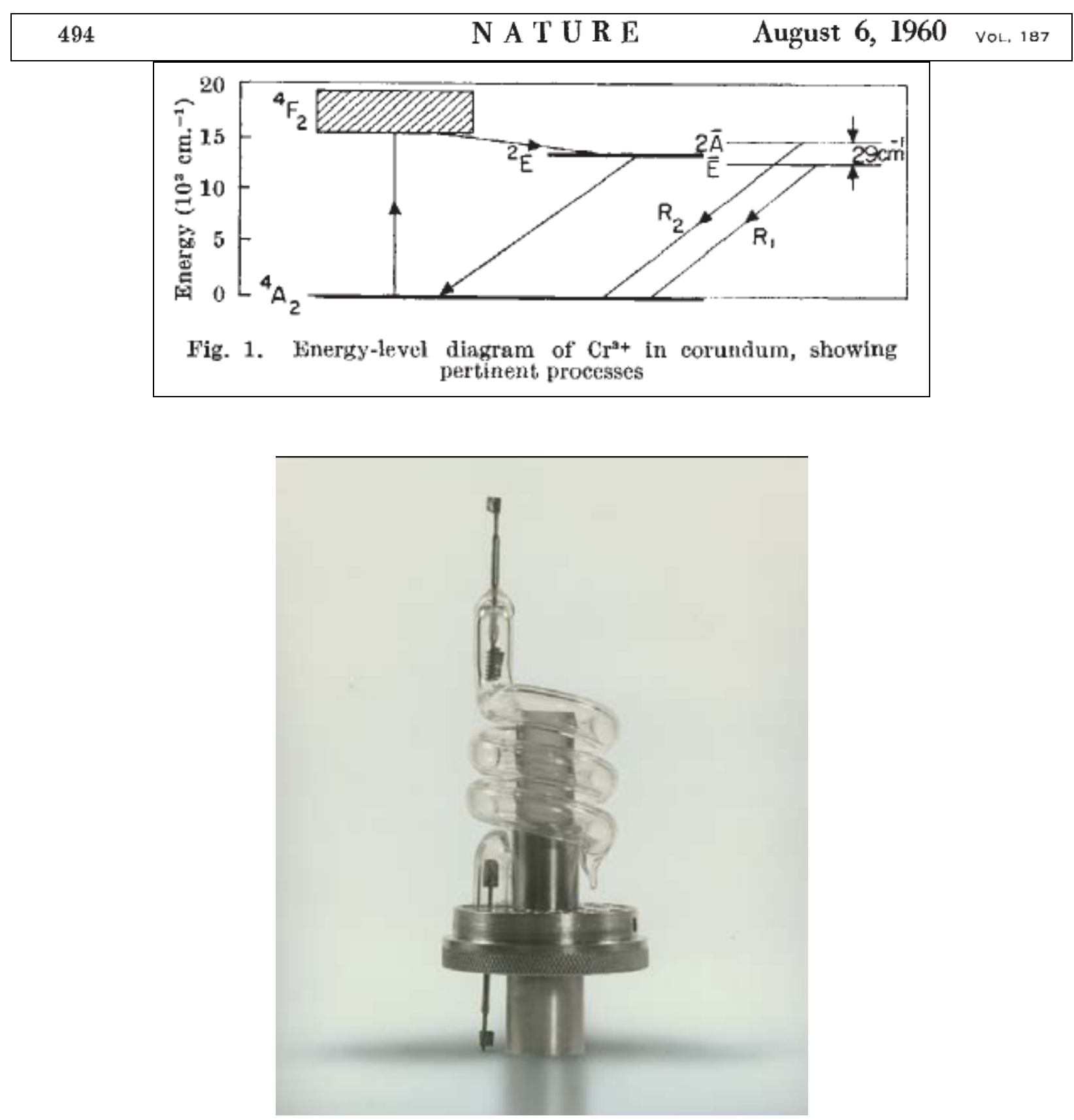

Fig 2. The first laser, without its reflective casing. 


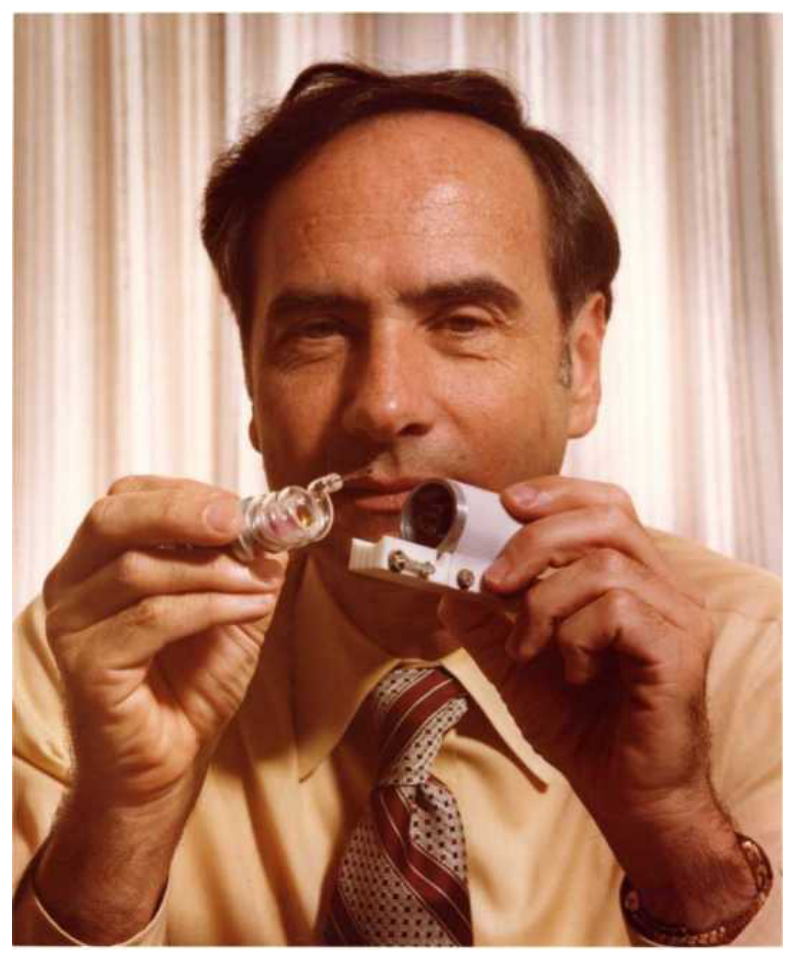

Fig. 3. Maiman and components of the first laser.

\section{AFTER-SHOCKS}

After a period of disbelief and denial from the well-funded competitors in the field, the laser was easily replicated by a number of researchers. The "presence effect", as Maiman frequently called it, might have caused an avalanche of subsequent developments of a variety of lasers. Peter Sorokin and Mirek Stevenson reported in November 1960 a cryogenically cooled uranium-doped, calcium-fluoride-based laser ("Stimulated infrared emission from trivalent uranium", Physical Review Letters Vol. 5., p. 557, 1960). One of the best funded groups in Bell Labs, headed by A. Javan, followed soon with an infrared He-Ne laser (A. Javan, W.R. Bennet, D.R. Herriot, "Population inversion and continuous optical maser oscillation in a gas discharge containing a HeNe mixture", Physics Review Letters, Vol 6, p. 106, 1961).

In 1961 and 1962 alone, some 12 different lasers appeared. The avalanche of new lasers based on modified principles still continues. Nowadays it is rather difficult to imagine life without some laser applications. When Maiman first demonstrated his laser, no-one really thought about what to do with it. Daily press coined the term "death ray" for the device. The earliest practical applications of lasers followed the maturing process of laser technology. Widespread use of lasers in material processing (drilling, welding, micro-welding, cutting, etc), in medicine (scalpel/cauterizer), entertainment, science, communication, data processing, military usage, mushroomed in early 1970s. Maiman himself made and patented several laser based inventions, including a projection TV which would not require focusing.

\section{AWARDS}

For the invention of the laser, Maiman received a large number of awards from a variety of distinguished sources. The first, the Fannie \& John Science Hertz award, was bestowed to him at the White House by President Lyndon Johnson. In 1983 Maiman received the Wolf Prize in Israel along with his good friend from Stanford times, Irvin Hahn, professor of physics at Berkeley. The Japan Prize, a scientific achievement equivalent to the Nobel Prize, established by Mr. Matsushita (founder and president of Matsushita Corp.), was presented to Maiman by the Emperor of Japan, His Majesty 
Hirohito. Apart from these distinctions, many world universities conferred Maiman with honorary degrees. For a reason which is increasingly less understandable for many scientists and journalists Dr. Maiman did not get Nobel Prize, even if he was three times nominated.

\section{MOVE TO CANADA}

In 1999, Ted and his wife Kathleen moved to Vancouver, British Columbia, Canada.

The author of this paper met Maiman in 2000 and invited him to join the School of Engineering Science at Simon Fraser University (SFU) as an adjunct professor. In 2002 Maiman was conferred an Honorary Degree from this university. In his convocation speech he addressed students with the following words:

"For those of you who are willing to take the risk of blazing new trials, you need to appreciate a reality of life: you will find that the more you deviate from conventional wisdom and the well-beaten paths, the more your consensus of agreement will diminish.

Naturally, if you achieve your goal in spite of going against established views, it is especially sweet. But even if your goal is not achieved, there is still a rich reward for your choice. You will experience the thrill and excitement of an adventure. I assure you it will not be boring."

\section{- Dr. Theodore Harold Maiman, Simon Fraser University 2002}

At over 70, Ted's age did not did not slow him down in his research projects. One sizeable room in the Maimans' home in Vancouver, was converted to a lab/workshop where Maiman spent hours working on a vertical start airplane. This was quite distinct project from the laser, but in it he utilized a laser-based gyroscope. His involvement in the School of Engineering Science at SFU was invaluable as he helped us to design Biophotonics, an academic program very close to his heart and the first of its kind in North America.

Theodore Maiman passed away on May 5, 2007 in Vancouver General Hospital, taking with him a number of great inventions and discoveries which he had conceived. On May $16^{\text {th }}$ of the same year, the date of the $47^{\text {th }}$ anniversary of the invention of the laser, Simon Fraser University organized a tribute to Maiman to celebrate his eventful life. Many friends and collaborators from the early days arrived and gave their accounts of his life, many of them focusing on him as an exemplary human being. Irnee D'Haenens, Maiman's collaborator, dear friend and a witness of the first laser trial, summarized the events preceding the demonstration of the first coherent light beam. The slate of speakers was concluded by Kathleen, Maiman's wife and friend of 23 years. Coincidentally, Irnee D'Haenens died of cancer just before Christmas 2007.

On this memorable meeting two decisions were made. The Ted Maiman bursary was created, for students with financial hardships researching applications of lasers in medicine; and the foundation for The Theodore Harold Maiman Collection (including the first, and still functioning, laser) was initiated. We are also collecting all materials related to life of Ted Maiman in preparation of writing a book about this exceptional man.

\section{REFERENCES}

P. Sorokin, M. Stevenson, "Stimulated infrared emission from trivalent uranium”, Physical Review Letters Vol. 5., p. 557,1960

W. Lamb, T. Maiman, "Measurement of the Fine Structure Separation $3{ }^{3} \mathrm{P}_{1}-3{ }^{3} \mathrm{P}_{2}$ for the Helium Atom", Review, Vol 105. No. 3, January 15, 1957

A. Javan, W.R. Bennet, D.R. Herriot, "Population inversion and continuous optical maser oscillation in a gas discharge containing a HeNe mixture", Physics Review Letters, Vol 6, p. 106, 1961

T.H. Maiman Stimulated Optical Radiation in Ruby. Nature, no. 4736, August 6, 1960

T.H. Maiman Stimulated Optical Emission in Fluorescent Solids. I. Theoretical Considerations Phys. Rev. 123, 1145 $1150(1961)$

T.H. Maiman et al., "Stimulated Optical Emission in Fluorescent Solids. II. Spectroscopy and Stimulated Emission in Ruby" Phys. Rev. 123, 1151 - 1157 (1961)

"Laser Pioneer Interviews" Lasers \& Applications, High Tech Publications, Inc, Torrance, California 1985

Jeff Hecht, "BEAM The Race to Make the Laser", Oxford University Press, 2005 
Theodore Maiman, “The Laser Odyssey”, Laser Press, Blaine, WA 2000

Transcripts of talks given by invited speakers on Theodore Maiman Tribute held at Simon Fraser University on May 16, 2008

Private communications with Theodore and Kathleen Maiman. 


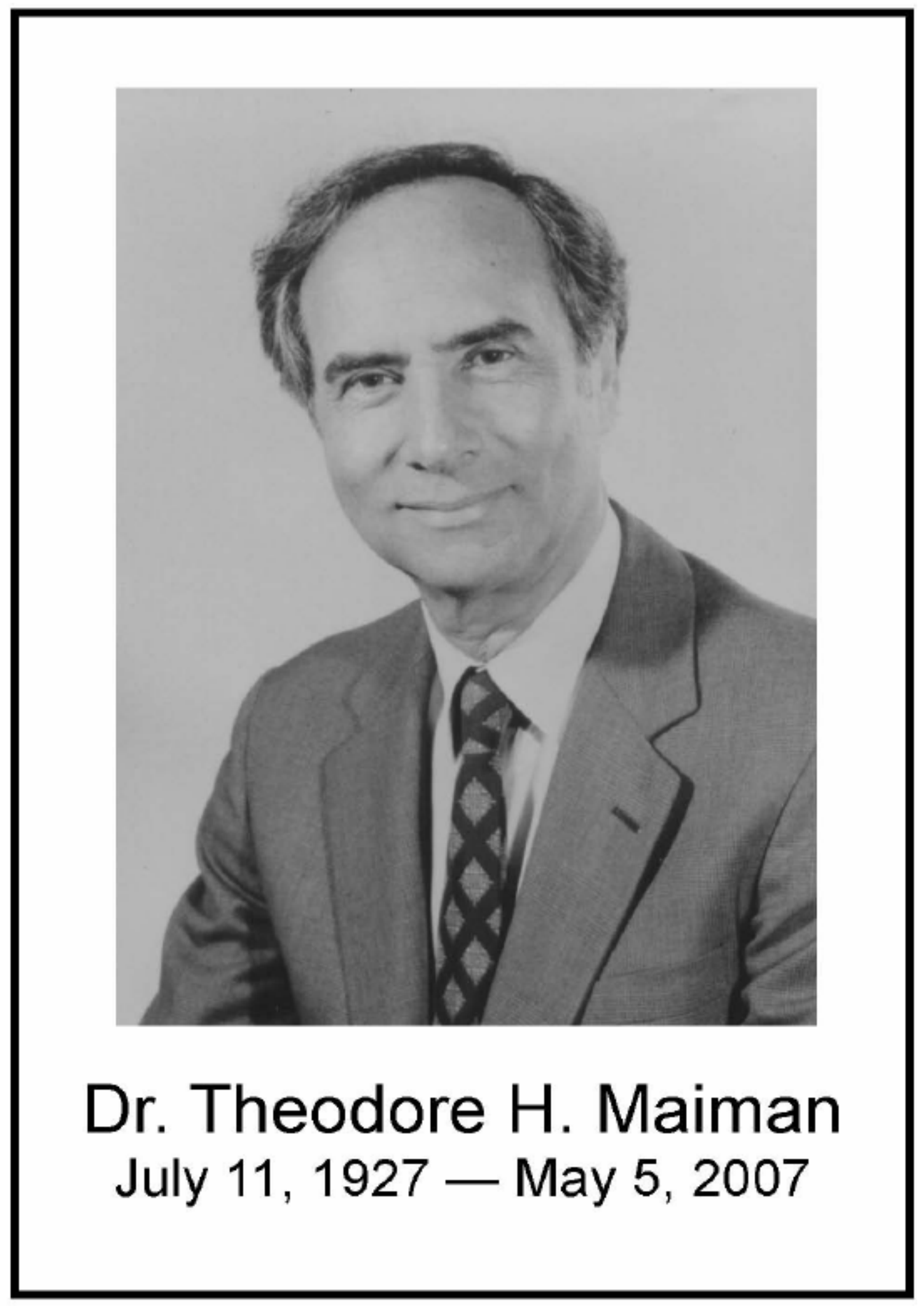

